\title{
Coletivos: poesia e endividamento
}

\section{Collectives: poetry and indebtedness}

\author{
Eduardo Coelho ${ }^{1}$
}

\section{Resumo:}

É importante destacar como o vocabulário financeiro se infiltrou na poesia brasileira contemporânea de jovens autores, em relação direta ou indireta com o problema do endividamento. Não por acaso, esse léxico da financeirização da vida foi se ampliando à medida que o neoliberalismo avançava durante os anos 2000 e 2010, quando a desigualdade socioeconômica foi se ampliando no mundo, ao mesmo tempo em que as tecnologias digitais traziam condições de novos atores se posicionarem na cena literária. O trabalho poético em torno do endividamento se manifesta como um dos aspectos mais instigantes da produção contemporânea no seu embate com questões do tempo presente, sendo um dos aspectos de consumação da impossibilidade de manutenção de certas tópicas da lírica, entre as quais o erotismo. O problema do endividamento na poesia brasileira contemporânea também pode ser analisado de uma perspectiva mais econômica e sociológica, dando a ver os paradoxos de uma fase em que o Brasil se lançou, concomitantemente, a políticas inclusivas e a pactos neoliberais, tão sintomáticos do lulismo.

Palavras-chave: Poesia. Coletivos. Endividamento.

1 Eduardo Coelho é professor do Departamento de Letras Vernáculas e do Programa de Pós-Graduação em Ciência da Literatura da Faculdade de Letras da Universidade Federal do Rio de Janeiro. É um dos coordenadores do Programa Avançado de Cultura Contemporânea - PACC, onde também coordena, com Luciana di Leone, o projeto de pesquisa, extensão e inovação Laboratório da Palavra. 


\begin{abstract}
:
It is important to highlight how much the financial vocabulary has infiltrated the contemporary Brazilian poetry of young authors, in direct or indirect relationship with the problem of indebtedness. It is not by chance that this lexicon of the financialization of life has been expanding as neoliberalism advanced during the years 2000 and 2010, when socioeconomic inequality was increasing in the world, at the same time that digital technologies brought conditions for new actors to place themselves in the literary scene. The poetic work around indebtedness manifests itself as one of the most exciting aspects of contemporary production in its confrontation with issues of the present time, being one of the consummation aspects of the impossibility of maintaining certain topics of the lyric, among them, eroticism. The problem of indebtedness in contemporary Brazilian poetry can also be analyzed from a more economic and sociological perspective, showing the paradoxes of a phase in which Brazil launched, simultaneously, inclusive policies and neoliberal pacts, so symptomatic of lulism.
\end{abstract}

Keywords: Poetry. Collective. Indebtedness.

No livro Declaração, Antonio Negri e Michael Hardt (2014, p. 9-17) recorreram à metáfora do "bastão" para descrever a "corrida de revezamento" em que, desde o início dos anos 2010, uma revolta popular era logo substituída por outra. Esse "bastão" chegou ao Brasil em junho de 2013, quando o coletivo Movimento Passe Livre convocou protestos contra o aumento do preço das passagens de ônibus, trem e metrô, levando, por fim, mais de um milhão e meio de brasileiros às ruas.

Contudo, a pauta desse coletivo, baseada no direito à mobilidade urbana, logo foi substituída por um repertório vastíssimo de questões e insatisfações, nem todas progressistas. Assim, passaram a coexistir reivindicações por escolas e hospitais públicos "padrão Fifa", em referência aos estádios que estavam sendo construídos para a Copa do Mundo de Futebol; exigiu-se maior segurança; combateu-se a política neoliberal, sustentada, em grande medida, no princípio de aquecimento econômico 
por meio da concessão de crédito fácil; ao mesmo tempo, erguiam-se bandeiras de intervenção militar e redução da maioridade penal, entre outros posicionamentos extremistas que iam resultar, a médio prazo, na eleição do presidente Jair Bolsonaro. Como esclareceu Raquel Rolnik no livro Cidades rebeldes, as manifestações de 2013 podem ser concebidas "como um terremoto [...] que perturbou a ordem de um país que parecia viver uma espécie de vertigem benfazeja de prosperidade e paz, e fez emergir não uma, mas uma infinidade de agendas mal resolvidas, contradições e paradoxos" (ROLNIK, 2013, p. 8).

Naquele momento de tumulto nacional, tornou-se evidente uma significativa transformação nos rumos da poesia brasileira contemporânea, especialmente se levarmos em consideração dois textos sintomáticos dos anos 1990 e 2000, respectivamente: o poema "A situação atual da poesia no Brasil", publicado em Collapsus linguae, de Carlito Azevedo (1991, p. 37), e o ensaio de Ricardo Domeneck "Ideologia da percepção ou algumas considerações sobre a poesia contemporânea no Brasil”, publicado no décimo oitavo número da revista Inimigo Rumor (DOMENECK, 2006, p. 175-216).

Nos únicos dois versos do poema de Carlito ("Não é cosa mentale/ é cosa nostra."), é possível observar uma sinalização para "o convívio sentimental e grupalmente fechado", em que há "uma clara consciência da articulação de [...] tribos, gangues ou pequenas máfias poéticas ('lei do grupo', 'cosa nostra'), consciência do próprio pertencimento e participação (é 'nostra', são 'meus amigos')", como analisou Luciana di Leone em seu livro Poesias e escolhas afetivas (LEONE, 2014, p. 89). A poesia brasileira contemporânea parecia então dividida apenas entre duas pequenas editoras, 7Letras e Azougue, que pouco interagiam entre si.

Já Ricardo Domeneck acentuou uma "situação incongruente" em que se encontrava a poesia brasileira do início dos anos 2000: ele mostrou que havia "expansão do número de autores e possibilidades de publi- 
cação e divulgação, com várias editoras criando novas coleções voltadas a poetas jovens, as possibilidades ilimitadas da divulgação pela internet, a multiplicação de revistas dedicadas à poesia", mas apresentava "o exíguo retorno por parte do público leitor, o isolamento dos poetas em pequenas coteries formadas por outros poetas, gerando entre nós a situação inédita [...] de serem os poetas hoje [em 2006] quase todos "poetas de poetas"" (DOMENECK, 2006, p. 175).

Desde o início dos anos 2010, no entanto, surgiram ou se consolidaram muitos coletivos de poesia e edição, realizando encontros abertos, uma administração descentralizada, ocupação dos espaços públicos e forte adesão a um viés político, que dedicava grande importância à conquista dos modos de produção e ao aproveitamento de novas tecnologias digitais para distribuir seus conteúdos de maneira autônoma, independente. Além disso, importa destacar que a maior parte desses coletivos foi criada em bairros de classe média baixa ou em favelas, onde continuam atuando por meio de debates, batalhas de slam, saraus, lançamentos de plaquetes e zines, num circuito paralelo à indústria cultural, embora não inteiramente, pois as redes sociais se tornaram um recurso de suas formas de circulação.

$\mathrm{O}$ aparecimento desses novos atores e de seus produtos trouxeram à poesia brasileira algumas novas figuras, que, de forma indireta, podem ser relacionadas a uma consideração de Antonio Negri e Michael Hardt em torno das "novas subjetividades de crise", surgidas de modo notável a partir das manifestações populares do início desta década:

O triunfo do neoliberalismo e sua crise mudaram os termos da vida econômica e política, mas também operaram uma transformação social e antropológica, fabricando novas figuras de subjetividade. A hegemonia das finanças e dos bancos produziram o endividado. (NEGRI; HARDT, 2014, p. 21, grifo do autor.)

Na poesia dos coletivos que surgiram em bairros de classe média 
baixa, decadentes, como o Méier, no Rio de Janeiro, percebemos diversas referências ao preço das coisas, às contas a pagar e ao endividamento, que podem ser localizadas na plaquete $O$ preço das coisas, lançada pela Oficina Experimental de Poesia e assinada por Ana Carolina Assis, Bárbara Coelho, Heyk Pimenta e Rafael Zacca. Dois de seus poemas revelam uma problematização do alto custo de vida e do endividamento, que foram trabalhados por meio do humor, do suspense e do campo afetivo-amoroso, todos entrelaçados, manifestando alguns traços de nonsense que perturbam a cena, como em versos de "Saíram para pagar a light":

saio pra ir pro açougue como quem sai pra pagar a light

o rosto das notas e moedas não as salva de nada

não encontro meus amigos

saíram de linha

saíram pra pagar a light

as moedas balançando no bolso enquanto se olham

foi o que conseguiram dizer antes de meter uma roupa

o cabelo foda-se

vou tomar café na rua e pago a light

e deixaram o boleto em cima da geladeira com 2 tapinhas de amizade

a rodoviária

emite passagens

de ida 
pra perto

cataguases peruíbe jacaraípe é o que paga

a grana da light pra março

querem ser cidades onde ninguém procuraria um cara

os amigos

joão saiu para pagar a light marcelo saiu

pra pagar a light mas voltou

pedro spahnol yuri de artur todos

saíram pra pagar a light

anaí rafa o luiz da $\mathrm{PUC}^{2}$

Não se trata de características específicas dessa plaquete: elas podem ser identificadas ainda em títulos da coleção MegaMini, como $\mathrm{Nu}$ vens [na seção de congelados] (2018), de Lucas van Hombeeck, e Surrado (2019), de Heyk Pimenta, ambos desse mesmo coletivo, a Oficina Experimental. Nessa última plaquete, lemos:

\section{IV}

comemos cheques e porcaria juntos em países diferentes

e fico mexido

se seus olhos olham pra câmera

nas fotos

eles entram em mim

passam a morar aqui

2 A plaquete $O$ preço das coisas não apresenta qualquer informação de caráter editorial, como editora e ano da publicação. 
os bato com os sonhos

tenho os ossos e as unhas moles tenho agiotas nas costelas e durmo com eles e somos irmãos

se houve chance e brasil

tenho planos cada vez mais modestos e saudade de quando o futuro organizava o amor mas vejo a fila e vejo a fila. (PIMENTA, 2019, p. 13.)

O problema do endividamento ou da falta de recursos já se apresentava no livro de estreia desse poeta, como podemos observar em dois versos de "O cobre das pombas", de Heyk Pimenta, publicado em Sopro sopro: "Uma calculadora praguejava/ seus salários que não davam conta" (PIMENTA, 2014, p. 58). Em sua poesia, as contas a pagar e os salários, insuficientes, participam de um cenário maior de desordem e podem ser compreendidos como um detalhe da vida cotidiana, mas que se faz presente e gera perturbação, impactando a vida afetiva.

Um caso provocativo do endividamento relacionado com o campo afetivo-amoroso pode ser observado no poema "O vício do crédito fácil", publicado no livro $O$ coice da égua, de Valeska Torres, autora de Inhaúma, que participa do Coletivo Audiovisual Miraluz Films e transita pelos coletivos feministas Mulheres que Escrevem e Respeita. Há versos desse poema que se apropriaram de características de anúncios de crédito pessoal, desnaturalizando-os por meio do humor e do estranhamento de matéria aparentemente tão avessa ao lirismo: "empréstimo? melhor dizer não! mas se for inevitável, mostramos como/ pagar o menos possível de 
juros" (TORRES. 2019, p. 59). Em seguida, a questão do endividamento desliza repentinamente da economia para o campo amoroso-sexual, que consiste num índice frequente na poesia brasileira contemporânea: "quase disse em voz alta,/ roberto de souza me prometeu gozos que nunca me deu/ e isso me frustra até hoje" (TORRES, 2019, p. 60). Obviamente, a promessa de gozo, antecedida por lugares-comuns de anúncios de crédito, parece se valer ao fundo de uma expressão popular brasileira: promessa é dívida! Portanto, nesse caso, o endividamento foi aproximado da experiência de perda, de carência, embora não tenha abandonado o recurso humorístico:

\section{O VÍCIO DO CRÉDITO FÁCIL}

\section{PARTE I}

não ache que o acesso imediato ao dinheiro pra realizar sonhos seja

motivo de comemoração

não se endivide para realizar o seu sonho de consumo

compre à vista e ainda tem troco

pág. 20

há opções bem em conta para você proteger o seu imóvel e pertences

de imprevistos como roubo e incêndio

pág. 33

empréstimo? melhor dizer não! mas se for inevitável, mostramos como

pagar o menos possível de juros

veja na pág. 10

que tal adquirir aquele smartphone dos sonhos ou trocar a velha

geladeira por uma novinha, isso sem recorrer ao 
parcelamento no

cartão de crédito

fundos de renda fixa crédito pessoal seguro carta verde

descumprimento de oferta limite de crédito $\mathrm{x}$ renda seguro residencial

nossos valores:

1. nossa missão exige uma neutralidade total

2. devemos desenvolver a capacidade de levar em conta as necessidades

de nossos interlocutores externos e internos

3. êxito de nossa missão é condicionado por nossa credibilidade e pelo reconhecimento dos melhores profissionais do mercado

\section{PARTE II}

se prometeu, tem que cumprir

wagner santos, fotógrafo

"fui à compra do frango cuja oferta havia sido anunciada na tevê à

noite. olhei nas prateleiras e não o achei."

quase disse em voz alta, roberto de souza me prometeu gozos que nunca me deu

e isso me frustra até hoje

wagner $\&$ eu, mesmo distantes, nos compreendemos 
ligamos, indignados, para o serviço de defesa do consumidor

disse a ela

meu ex acreditou todas as vezes que eu disse gozei

disse não sei o porquê de tantas mentiras mas quando se ama fazemos

coisas que não sabemos bem o motivo

estava carente e queria gozar, estava carente precisava

a telefonista bateu forte o telefone, do outro lado da linha (silêncio)

e eu ainda pedia o meu gozo

os meus segundos com a telemarketing que não compreendeu as coisas que se perdem quando se ama.

(TORRES, 2019, p. 59-60.)

Outra estratégia de abordagem do problema do endividamento se manifesta mediante a ironia de "Une chanson (alô? está me ouvindo)", publicado em Três semblantes, de Lucas Matos, do coletivo Bliss não Tem Bis. Iniciado pelo seu refrão - "ninguém vai ter amar/ tanto quanto o seu credor" (MATOS, 2015, p. 21) - esse poema explora as canções de amor francesas, numa relação obsessiva entre o credor e o endividado. Apesar do humor também presente nesse poema, seus versos apresentam uma situação de um sujeito sem saída, que teve seu tempo sequestrado pelas dívidas: "a mãe está no hospital/ e é para você que ele/ liga no sábado de manhã" (MATOS, 2015, p. 21): 


\section{UNE CHANSON (ALÔ? ESTÁ ME OUVIN- $\mathrm{DO}$ ?)}

ninguém vai ter amar

tanto quanto o seu credor

nem o pai nem a mãe

e os filhos se você tiver

vão te amar menos

vão amar sempre menos

ninguém vai ter amar

tanto quanto o seu credor

a mãe está no hospital

e é para você que ele

liga no sábado de manhã

ninguém vai te amar

tanto quanto a esposa

mandou uma carta

para a amante tudo

parece ir para as

cucuias e é o teu

email que ele procura

ninguém vai te amar

tanto quanto o seu credor

o pai já não sabe quem é

o cachorro morreu

o filho mordeu os amigos

e quando ele sai para

passear com o bicho

sente a corda apertar

em torno do pescoço

é teu nome

que ele sussurra 
com teu nome

que ele engasga

ninguém vai te amar tanto quanto o seu credor

nem à primeira vista

nem o primeiro amor

nenhum casório

nenhum estranho

no carnaval que te beijou

ninguém vai te amar

tanto quanto seu credor

(MATOS, 2015, p. 21-22)

Nesse mesmo livro, Lucas Matos abordou o problema do endividamento como o único ponto de interseção possível entre todas as diferenças e desigualdades do nosso tempo. $\mathrm{Na}$ " 9 a tese" da personagem dessa série, Marianne K., ele escreveu em caixa-alta:

SÓ A DÍVIDA NOS UNE. O QUE HÁ EM

COMUM ENTRE UM

HOMEM QUE RECEBE MENOS QUE UM

SALÁRIO MÍNIMO,

UM BANQUEIRO, BICHOS SELVAGENS, UMA EMPRESA, UM ESTADO, ESTRELAS, IDEIAS,

CASCA DE BANANA? TODOS ESTÃO EM DÍVIDA. TEM PODER

AQUELE QUE PODE COBRAR MAIS QUE OS OUTROS, E NÃO TEM PODER AQUELE QUE SEMPRE PAGA, PAGA A VIDA INTEIRA

E PASSA TODOS OS DIAS A PAGAR. 
(MATOS, 2015, p. 28.)

Dessa maneira, encontramos na poesia de Lucas Matos uma perspectiva crítica tragicômica, às vezes apocalíptica, em que as ideias de perseguição e limitação do tempo estão diretamente associadas à precarização do trabalho, ao aumento do custo de vida e à dinâmica perversa do consumo neoliberal. Não é de se estranhar que a questão do endividamento, das contas a pagar e do preço das coisas tenha surgido justamente no momento em que a poesia brasileira se abriu a novos protagonistas, que reinventam a condição marginal do poeta da modernidade.

No artigo "O aumento do endividamento das famílias durante o governo Lula" (2016), os economistas Jéssica Aparecida Belliomini de Camargo e Manuel Antonio Munguia Payés apontaram que, conforme um relatório da Mckinsey Global Institute realizado em 2015, consta que o endividamento no Brasil é maior que sua própria renda, o que tem se agravado de lá para cá. Não à toa, o endividamento se tornou um lugar-comum em versos da literatura brasileira atual. Pela recorrência do assunto, pelas questões subjacentes ou não que o acompanham, e pela mudança de estatuto econômico do poeta - antes sem dinheiro e agora endividado -, torna-se interessante avaliar como essa "nova subjetividade" está sendo problematizada pela poesia brasileira contemporânea e quais suas implicações.

Nesse sentido, é importante destacar que o endividamento surge, às vezes, como um traço corriqueiro, factual, quase naturalizado, que não impacta efetivamente na construção de uma subjetividade. Nesses casos, o endividamento consiste num índice de desordem que se encontra misturado a muitos outros, como a infelicidade profissional, o trânsito engarrafado e a violência urbana. Por outro lado, a naturalização do endividamento talvez resulte de um pastiche dos anúncios de crédito fácil.

Contudo, a ideia de perseguição que se revela de modo criativo na poesia de Lucas Matos deixa em evidência o caráter perverso do 
capitalismo financeiro, especialmente ligado à dívida, conforme Maurizio Lazzarato apontou em $O$ governo do homem endividado "constitui uma nova técnica de poder [...], de controle e de coerção sobre o devedor" (LAZZARATO, 2017, p. 66). A dívida irrompe, muitas vezes, como um fator de controle sobre o tempo do endividado, e este tempo confiscado do sujeito se entrelaça a um estado de profunda melancolia, como se pode constatar no poema "Sofá", do livro Um rojão atado à memória, de Estela Rosa, do coletivo Mulheres que Escrevem:

O cheiro da calça jeans entra pelas narinas e penso: não há nada que possa fazer pra sair desse marasmo que é a vida. Quanto mais procuro entender que de pouco me adiantam os números, as letras, os cartões de débito ou crédito, concursos públicos, cadernos brochura ou pirex de vidro temperado, mais descubro que é necessário acumular dívidas, livros e cabelos molhados no ralo. $\mathrm{O}$ cheiro cansado da calça jeans sobre o sofá não remete a nenhum feito admirável, nenhum suor foi gasto nessa cena, nada de gozo, apenas aquele acúmulo de bancos de carro, restaurante, pingos de café e cheiro de dinheiro no bolso de trás. E ainda que isso não pareça ter importância, sigo acordando, assustada, no meio da madrugada, para procurar nos bolsos da calça quase suja o resto de horas que me faltam para poder descansar. (ROSA, 2019, p. 22.)

A descoberta da necessidade de "acumular dívidas" - que já se tornava presente por meio da referência ao cartão de crédito - está inteiramente inserida num cenário dominado pela exaustão e pela ausência "de gozo". A calça jeans suja, tão característica da contracultura, não pode ser associada a qualquer "feito/ admirável". Antes, em seu poema "Suaves parcelas", uma estrofe se constitui de apenas um verso: "Não tenho perspectivas" (ROSA, 2019, p. 19). Sem dúvida, nos versos desses dois poemas, a culpa se manifesta como outro fator de relevância na proposição 
do endividamento do sujeito.

Antonio Negri e Michael Hardt afirmam em Declaração: "Atualmente, ter dívidas está se tornando a condição geral da vida social." (NEGRI; HARDT, 2014, p. 22). Enfim, trata-se de uma necessidade. Em seguida, analisam:

O efeito da dívida, como o da ética do trabalho, é forçá-lo a trabalhar arduamente. Enquanto a ética do trabalho nasce no interior do sujeito, a dívida começa como uma coação externa, mas logo segue seu caminho tortuoso rumo ao interior. A dívida exerce um poder moral cujas armas principais são a responsabilidade e a culpa, que podem rapidamente se transformar em objeto de obsessão. Você é responsável por suas dívidas e se culpa pelas dificuldades que elas criam em sua vida. $\mathrm{O}$ endividado é uma consciência infeliz, que faz da culpa uma forma de vida. Aos poucos, os prazeres da atividade e da criação se convertem num pesadelo para aqueles que não possuem os meios de aproveitar suas vidas. A vida foi vendida ao inimigo. (NEGRI; HARDT, 2014, p. 22-23.)

É importante destacar como o vocabulário financeiro se infiltrou na poesia brasileira contemporânea de jovens autores, em relação direta ou indireta com o problema do endividamento. Não por acaso, esse léxico da financeirização da vida foi se ampliando à medida que o neoliberalismo avançava durante os anos 2000 e 2010, quando a desigualdade socioeconômica foi se amplianda no mundo, ao mesmo tempo em que as tecnologias digitais traziam condições de novos atores se posicionarem na cena literária. Esse vocabulário se liga à culpa, à melancolia e à exaustão, bem como à falta de perspectivas, compreendendo muitas imagens de acúmulo de boletos, perseguição e asfixiamento, não raro acompanhadas de um nonsense perturbador, de caráter surrealizante. $\mathrm{O}$ trabalho poético em torno do endividamento se manifesta, assim, como um dos aspectos mais instigantes da produção contemporânea no seu embate com questões do tempo presente, sendo um dos fatores de consumação da impossibilidade 
de manutenção de certas tópicas da lírica, como o erotismo. O problema do endividamento na poesia brasileira contemporânea também pode ser analisada de uma perspectiva mais econômica e sociológica, dando a ver os paradoxos de uma fase em que o Brasil se lançou, concomitantemente, a políticas inclusivas e a pactos neoliberais, tão sintomáticos do lulismo.

\section{Referências}

ASSIS, Ana Carolina; COELHO, Bárbara; PIMENTA, Heyk; ZACCA, Rafael. O preço das coisas. S./1.: s./e., s./a.

AZEVEDO, Carlito. Collapsus linguae. Rio de Janeiro: Editora LYNX, 1991.

CAMARGO, Jéssica Aparecida Belliomini de; PAYÉS, Manuel Antonio Munguia. $\mathrm{O}$ aumento do endividamento das famílias durante o governo Lula, $€$ co\$, Sorocaba, v. 6, n. 1, p. 99-114, 2016. Disponível em: <periodicos.uniso.br/ojs/index.php/ecos/article/download/3440/3039/>. Acesso em: 7 ago. 2019.

DOMENECK, Ricardo. Ideologia da percepção ou algumas considerações sobre a poesia brasileira contemporânea. Inimigo Rumor, n. 18, p. 175216, $2^{\circ}$ semestre $2005 / 1^{\circ}$ semestre 2006.

HOMBEECK, Lucas van. Nuvens [na seção de congelados]. Rio de Janeiro: Megamíni, 2018.

LAZZARATO, Maurizio. O governo do homem endividado. Tradução de Daniel P. P. da Costa. São Paulo: n-1 edições, 2017.

LEONE, Luciana di. Poesia e escolhas afetivas: edição e escrita na poesia contemporânea. Rio de Janeiro: Rocco, 2014. [Coleção Entrecríticas.]

MATOS, Lucas. Três semblantes. Rio de Janeiro: 7Letras, 2015.

NEGRI, Antonio; HARDT, Michael. Declaração - isto não é um manifesto.

Tradução de Carlos Szlak. São Paulo: n-1 edições, 2014.

PIMENTA, Heyk. Sopro sopro. $3^{\text {a }}$ ed. São Paulo: Edições Maloqueiristas, 2014. 
. Surrado. Rio de Janeiro: Megamíni, 2019.

ROLNIK, Raquel. Cidades rebeldes. São Paulo: Boitempo, 2013.

ROSA, Estela. Um rojão atado à memória. Rio de Janeiro: 7Letras, 2019. TORRES, Valeska. O coice da égua. Rio de Janeiro: 7Letras, 2019.

Recebido em: $21 / 08 / 2020$

Aprovado em: 23/08/2020 